DOI: $10.1515 /$ hssr -2016-0011

\title{
To Communicate is to Negotiate
}

Dominique Wolton*

CNRS, Paris, France

\begin{abstract}
Considering that the beginning of the $21^{\text {st }}$ century saw the emergence of a third meaning of the word "to communicate" - to negotiate, the author sets out to explore the challenges it supposes in today's dangerous, multipolar world, where the respect for alterity and the construction of cohabitation have become the keys of peace and war. The author concludes that the political challenge of communication in the $21^{\text {st }}$ century will be to enable the peaceful cohabitation of the same and the different in open societies, where economy will no longer be the only horizon of human beings.
\end{abstract}

Keywords

Communication, Negotiation, Cohabitation, Self and the Other

The rupture of the $21^{\text {st }}$ century is, undoubtedly, the emergence of the third meaning of the word communication: to negotiate. It comes after the meaning "to transmit" and "to share", and it concerns the central question: how to live together peacefully in a world that has become very small, transparent, in which differences, thanks to technologies, are more perceptible than similarities? How to prevent communication which, a while ago, would bring individuals close to each other, from becoming nowadays an accelerator of incomprehension, and even hostility or, in any case, of distance between societies whose differences are much more perceptible? The concept of co-habitation has become central in the $21^{\text {st }}$ century. We have passed from the seeming certitude of information in

*Institut des sciences et de la communication (CNRS), contact.wolton@cnrs.fr 
the $20^{\text {th }}$ century to the uncertainty of communication in the $21^{\text {st }}$ century.

Today's multipolar world is more complicated and dangerous than yesterday's world because tensions are added to political, economic and social conflicts. This is the question at the beginning of the century. The $19^{\text {th }}$ century was the century of politics with democracy, the $20^{\text {th }}$ century - the century of economic and social issues with the reduction of inequalities, the $21^{\text {st }}$ century, at least in its beginning, is the century of communication, that is of negotiation and cohabitation.

The triangle identity-culture-communication can become the infernal triangle of the $21^{\text {st }}$ century. The respect of alterity and the construction of cohabitation become the keys of peace and war. The seduction technique no longer suffices to halt these contradictions of a new type, because whereas cultural differences have always existed, technical globalization accelerates their visibility. On the contrary, communication technologies have had an extremely positive role, that has been insufficiently valorised for half a century: to mitigate the shock of the opening of the world on itself. They have simultaneously ensured this opening and reduced the destabilisation that it caused among individuals and peoples who could see the world from their homes. They have acted as mediation.

By opening the world on itself, they have certainly much disturbed representations, but at the same time, they have sensitised the public to this new reality of an open world, with its similarities and differences. By relying on the performance of technologies, humans also attempt to preserve a connection, or even to keep hold, just so as to absorb the shock of alterity. "Classical" or "recent" communication technologies have a contradictory role: to make more visible, and therefore more conflictual, differences of culture and civilisation, to make more comprehensible this world that they have contributed to open.

However, progressively, this technological revolution has become the "loincloth" of in-communication. It is now imperative to leave behind the myth of "the free individual, over-connected, naturally altruist and curious, living in an online society where everything is just pacifist relations". The result is totally different given the violence of the world, the complexity and irrationality of human and social communication, without ignoring the power of "com" industries; especially as the 
difference between interaction and communication is increasing. There will be more and more interactions and interactivity, including with intelligent objects, RFID and nanotechnologies, and we shall all the more guess, painfully, that inter-comprehension is not improved. The more numerous and fruitful the interactions are, the more necessary it will be to differentiate the strengths and weaknesses of human communication. The better technologies perform, the more necessary it is to highlight what separates them from communication.

The problem is not the hierarchy of technologies between "old" and "new" media, but to understand how the media and the Internet manage, each in their own way, these two dimensions that are inherent to information and communication: the normative and the functional dimension. They take charge, differently, of the most important aspect: human and social relations. The media, less performing technically than the Internet, are better equipped to tackle the question of alterity. The Internet, on the other hand, is more efficient to ensure community communication, in which cultural similarities facilitate normative communication. Conversely, the new technologies are less adapted to a heterogeneous communication connected to an open society.

On the one hand, there is one communication in which alterity dominates; on the other hand, a community of values prevails. Once again, it is not technical performance that is the most important, but the intentionality with which these two eternal dimensions of communication are managed: the normative and the functional dimension. These are two dimensions which, let us recall, do not set man against technology, because there are very numerous situations in which normative communication is on the side of technologies, and functional communication on the side of men...

What is the essential challenge of communication? The other and alterity. We do research on the same, and we negotiate with the other. And we understand why technological performance allows the delay of facing this question. Up to what point will the speed of the transmission of information, the pseudo-transparency of human relations, the generalised interactivity, the apparent information-communication continuity, the access that is always facilitated to ever more information, counterbalance the slowness of human communication, the weight of 
silences, the discontinuity of relations, the slowness of decisions and of action, the irrationality of human and social relations? The difficulties of human communication have always existed; what is radically new is the change of the cultural model which turns communication into a sort of "natural" obligation.

To communicate has become synonymous with to live. This is the attribute of freedom. So much the better, but on condition that one should not confound technical performance with the existential difficulties of human communication. Thus, technology becomes, simultaneously, better allied to and the enemy of communication. This is why one has to criticise the technical ideology, when it turns technologies into the cause of the emergence of an ideal society. Computers do not create a new society. Conversely, it is indispensable to find again the political utopias behind the new technologies. The revalorisation of utopias allows us to prevent technology from becoming utopia.

To highlight the difference of nature between information and communication is equally indispensable for another reason. In the past, information would make us think of the idea of the event and rupture. Nowadays, everything is event, and information becomes a sort of continuous flow, to which anyone can connect when he or she wishes to. On the other hand, communication in the past was more on the side of the flow. In the contemporary world, in which alterity imposes itself and in which, on the contrary, one has to observe cohabitation, it becomes more sequential. It itself manages discontinuities and negotiation. The two concepts remain inseparable, but in a normative perspective, quasi opposed to the one in which they were thought of in the $18^{\text {th }}$ century.

We can mention here the five essential ruptures of the communicational turn in the $21^{\text {st }}$ century.

Communication has become a more complex issue than information, since it concerns relation, therefore one's rapport with another. This gap symbolises the emergence of the increasing role of the recipient, who filters messages more and more, negotiates interactions and slightly becomes the symbol of the fact that to inform is not to communicate. To communicate means to be faced withalterity; extracting oneself from technology so as to find humans and society again, and to negotiate. We 
could even say that the difference between human and technical communication is precisely the reality of incommunication, which does not exist in technical communication. There is incompatibility, but not incommunication. Machines get connected, distribute, interact; it is only humans who know the test of incommunication.

Therefore, the central question, for peace and war, is the management of alterity. How to live together peacefully, when differences are more visible and real than similarities? Especially as nobody wishes to abandon his or her specificities. To admit the weight of alterity is to recognise the weight of the collective cultural identity, therefore the reality of cultural diversity and the horizon of cohabitation. The simultaneous reference to universals prevents one from enclosing cultural diversity in communitarism, and politics in the rejection of the other and populism. To bring together the respect for diversity and universalism is the new normative horizon of an open world. This begs one to bring together two perspectives: those of identity and cultural diversity.

One cannot talk about a political, cultural and pacific cohabitation in the absence of the establishment or reinforcement of secularism, the only way of avoiding the overlapping of the political and the religious... Secularism means a peaceful cohabitation of religion and politics. Cultural identity-secularism-universalism thus represents the three conditions behind the invention of a cultural cohabitation which would not be threatened by communitarism, or by the return of religious control over politics. Secularism remains one of the main cultural and political concepts through which one can conceptualise otherness, cultural cohabitation and universalism. Under different forms, Europe has a strong experience of it that it cannot capitalise on.

It is certainly important to render more visible the conflict of legitimacies, which I have been signalling for many years, in order to highlight the difference between information, knowledge and action. These three ways of relating to the world are essential and complementary, though often contradictory. What differentiates them needs to be strongly reasserted, otherwise the public space would become anarchic, cluttered with antagonist visions, which overlap and compete with each other, without enabling people to identify with any of them. The implied risk is that of anomie. Everything can cohabitate in 
the public, open and enlarged space, provided that everyone should easily identify the different ways of relating to the world represented by these three visions.

From this perspective, Europe is the greatest building site of political cohabitation in history, as it strives to help cohabitate twenty-seven states with twenty-six different languages and five hundred million Europeans. This is what I would call a positive experience at world scale! It is only Europeans who fail to be proud of the history that they are making. Let us imagine globalization without this huge building site which has existed for 50 years. What would it look like? A classical game of force relationships and of wars. Europe is the only reality which has been incarnating invention in politics for the past fifty years. One advances step by step, in economy and a little bit in politics and culture, guiding oneself only by compass of the need to cohabite. When we look at the difficulties that Europe has had to deal with but has always overcome, the "fatigue of the old continent" seems to be a countermeaning and a lack of vision on the challenges of history. It would suffice to look at the difficulties that the future building site would face outside of Europe, when trying to bring people together, in order to fulfil the avant-gardist elements of Europe.

The essential break-up may be found with the knowledge to be built in order to think about this open world, in constant interaction and without too much hierarchy. In order to achieve this, one has to interrogate history and try to understand the scope of differences. One has to mobilize all the sciences, from politics to economy, from history to anthropology, from cognitive sciences and engineering to environmental sciences, as well as communication... in order to reflect, thanks to interdisciplinarity, on the new communication-globalization pair. However, one should not forget, the essential role played by literary, religious, journalistic, artistic, aesthetic experiences, which can often be just as explanatory as sciences. An immense effort of knowledge is thus required to reflect on how communication is one of the requirements of tomorrow's peace and war, having no relationship with the omnipresence of the current technical interactions.

During the last century, facts have been quicker than analyses. This explains why a great diversity of knowledge and approaches is required 
in order to reflect on all these breaks. Unfortunately, this diversity of approaches contradicts the economic reality, which goes in the opposite direction, that of a growing rationalization of industries and of knowledge. Everything becomes standardized at world level, as we can already see with the industries of culture and communication. Signing the Convention for the respect of cultural diversity in 2005 was meant to foster diversity, but in fact it has not slowed down the concentration of the culture and communication industries. The same holds true for knowledge. The advantages of diversity are constantly mentioned, only to be denied afterwards. The diversity of techniques does not strengthen the diversity of contents. The same observation is true for information. There have never been so many supports, and yet world visions have not become more tolerant. Societies do not grant themselves the means to reflect on these changes of scale, which are even more complicated than those concerning ecology, as here we are dealing with the lives of persons, cultures and societies.

From information to communication, culture and knowledge, globalization is not so easily synonymous with diversity. If we were to provide instances of such theoretical building sites which should be opened in order to conceptualize an open world, but hardly observing diversities, we should cite the discontinuity between information and communication; the end of physical differences and the increased visibility of cultural distances. What happens when everybody sees everything and knows everything? The expansion of interactive solitudes; the gap between the performance of technical systems and human incommunication; the omnipresence of speed and the unbearability of time; the incapacity of thinking otherness within a small and transparent world; the respect for cultural diversity, the rejection of linguistic diversity and the reign of monolingualism; the triple tyranny of transparence, interactivity and security; the growth of communitarisms in the name of the right to differences... and the list of subjects to ponder on could continue.

This growing complexity of the relations between information and communication is also to be found in a neighboring field, which is essential for the peace of tomorrow: the field of knowledge which, in its turn, is invaded by the commodification of knowledge that both throws 
off and seduces academic communities. These communities are in their turn won over by rationalization, efficacy, competition, hierarchy, though a priori, they are the bearers of other values than those of financial capitalism. An example? There is nothing but ranking, racing and competition in world universities, the war for the Nobel prize, the seclusion of the best teachers and students coming from all over the world in paradise campuses. There are fewer and fewer insolences, less and less "futile" knowledge, erudition, artistic culture, wacky debates, or simply humour and fun. Everything is becoming homogeneous and demure. The academic world takes after the economic one. The "great" universities look like companies, with lawns and sports halls. Knowledge is reduced to an instrument of power, and communication to a grinning short circuit.

Thus, the status and the responsibility of the elite are also called into question. Will they end up accompanying a phenomenon of globalization and rationalization in communication, just as in information and knowledge, or will they be able to maintain other values? In particular the value of general interest, of the respect of other logics of knowledge, of the refusal of world hierarchy, of generosity, beyond the reign of deregulation.

In fact, distress comes to he or she who asks questions, criticizes or makes ironic comments. Such persons are quickly labeled the enemy of "progress", the defender of the past... All over the world, the elites and consequently, the overwhelming majority of university communities have noisily converted to this worldwide competition of knowledge, accompanied by a strange submission to technical ideology, which offers no critical resistance to the multiple promises of the knowledge web, interactive universities, knowledge and data banks. The worst thing is certainly the fact that the academic community directly borrows the vision of companies, even though, given the dominant economicism, maintaining differences of vision is more important than ever. Over the past 30 years we have been witnessing the alignment of the academic community to a largely insufficient economic reality. The University had learned to keep its distance from the Church, but it cannot do so from economy.

Once it has entered modernity, simultaneously with the idea of 
individual freedom, communication, flanked as it is now by these two "i"s: identity and information, represents one of the main contemporary concepts used to conceptualise the beginning of the $21^{\text {st }}$ century. The latter is both confronted with the globalization of information and with the triumph of cultural diversity, two essential splits which come down to communication and could determine both peace and war.

These two words, information and communication, do not only imply a technical choice, but also two conceptions of the world of knowledge. In one case, a world of knowledge rationalizes itself and turns into a world industry, just like the others. In the other case, an aggiornamento of the universe of knowledge through expansion to other social and anthropological dimensions. It is from this perspective that information and communication, far beyond the technical, political and cultural challenges already discussed, are situated at the core of an epistemological revolution, the one concerning the definition and status of knowledge in an open world.

Unfortunately the debate has not begun yet, but it signifies two things. First, the existing, narrow and insufficiently analyzed link between the revolution of information, communication and the status of knowledge. Information and communication are at the core of the readjustment of sciences, but also of debates on the mutations of the role of knowledge in the world. Second, it is mandatory that academic communities and the elite assume responsibility for conceptualising this revolution of information and communication. This is a revolution which modifies the functioning of the world and therefore its organization since, for the first time in history, the world is becoming "instantaneous." This has a fundamental impact on the production of representations in our open and small world. Will people pursue a unique model, an occidental one, of the relationships between science, technique, culture and society, with its forces, weaknesses and its process of rationalization? Or will we witness, on the occasion of this globalization, which is also a reexamination of the relationships between the other and the universality, the emergence of the problematics of diversity, with its unavoidable power relations? To put it differently, knowledge, just as communication, is confronted with the question of diversity and with the obligation to rethink the relationships between diversity and universality. 
HSS, vol. V, no. 2(2016): 13-22

In both cases it is the relationship with the other which is as stake, or rather the degree to which one takes into consideration otherness - that is the different forms of cohabitation - in communications, as well as in knowledge. To valorise cohabitation, which is in fact placed at the centre of the democratic model, also means to reflect on ways to escape a too economical and rationalist vision of society. To rehabilitate the issue of cohabitation thus means to exit the dominant economicist ideology and to recall that societies have other goals, among which that of living together, while being different from one another. This quest for cohabitation, as a new horizon of globalization, could become utopian and find a supplementary value in this political approach to communication, which privileges negotiation and cohabitation.

What would the political challenge of communication be? To enable the peaceful cohabitation of the same and the different in open societies, where economy will no longer be the only horizon of human beings. Would that be utopian? Certainly so, and so much the better, as this third globalization creates a need for utopia in order to prevent the omnipresence of information and of communication, instead of bringing closer different points of view, and endangers even more the fragile balances of peace and war at the beginning of this new century.

\section{Biographical note}

Dominique Wolton is a Doctor of sociology and a graduate of the Institut d'Etudes Politiques de Paris. He founded the international journal Hermès (published by the CNRS), which he has headed since 1988. His main field of research concerns an analysis of the relationships between culture, political communication, Europe and the internet. For more than 30 years he has developed a reflection that places communication in the center of the concerns about the future of democracy, globalization and the relations among peoples and civilizations. He mainly authored Éloge du grand public. Une théorie critique de la télévision (1990); Penser la communication (1997); L'autre mondialisation (2003); Informer n'est pas communiquer (2009); La communication, les bommes et la politique (2015) 